\title{
Rationale and development of image-guided intensity-modulated radiotherapy post- prostatectomy: the present standard of care?
}

This article was published in the following Dove Press journal:

Cancer Management and Research

II November 2015

Number of times this article has been viewed

Julia R Murray ${ }^{1,2}$

Helen A McNair ${ }^{2}$

David P Dearnaley ${ }^{1,2}$

'Academic Urology Unit, Institute of Cancer Research, London,

${ }^{2}$ Department of Radiotherapy, The Royal Marsden NHS Foundation Trust, Sutton, UK
Correspondence: David P Dearnaley Department of Academic Radiotherapy, The Royal Marsden Hospital, Downs Road, Sutton, Surrey, SM2 5PT, UK Tel +44 208661327 I

Email david.dearnaley@icr.ac.uk

\begin{abstract}
The indications for post-prostatectomy radiotherapy have evolved over the last decade, although the optimal timing, dose, and target volume remain to be well defined. The target volume is susceptible to anatomical variations with its borders interfacing with the rectum and bladder. Image-guided intensity-modulated radiotherapy has become the gold standard for radical prostate radiotherapy. Here we review the current evidence for image-guided techniques with intensity-modulated radiotherapy to the prostate bed and describe current strategies to reduce or account for interfraction and intrafraction motion.
\end{abstract}

Keywords: radiotherapy, prostate cancer, post-prostatectomy, image-guided radiation therapy

\section{Introduction}

Over the last three decades, external beam radiotherapy has evolved as a result of improvements in radiotherapy planning software, delivery, and introduction of computed tomography (CT)/magnetic resonance imaging (MRI)-based planning. Prostate radiotherapy has also evolved with these technological advancements, enabling dose escalation. ${ }^{1-3}$ Comparative data suggest that intensity-modulated radiotherapy (IMRT) reduces particularly gastrointestinal (GI) toxicity compared with threedimensional conformal radiotherapy (3D-CRT). ${ }^{4}$ IMRT allows not only sparing of organs at risk, but also irradiation of different tumor targets at various dose levels, known as simultaneous integrated boost techniques. ${ }^{5}$ Optimizing the conformality of radiation dose requires increased set-up precision. Therefore, methods to improve precision of planned dose delivery have been developed with image guidance, in addition to ways to stabilize the target volume.

Prostate cancer is the second most common cancer in men worldwide, and more than 1.1 million cases of prostate cancer were recorded in 2012. This accounts for $15 \%$ of the cancers diagnosed in men, with almost $70 \%$ of the cases occurring in the more developed regions. ${ }^{6}$

Radical prostate radiotherapy and radical prostatectomy (RP) are considered the mainstay of management for localized prostate cancer. The number of RPs performed worldwide is increasing. ${ }^{78}$ This increase is due to more patients being diagnosed with localized prostate cancer as a result of increased availability of prostate-specific antigen (PSA) testing, , reduced morbidity associated with RP performed by "high volume" surgeons, ${ }^{10}$ and the developing role of RP as part of multi-modality treatment for patients with high-risk prostate cancer. ${ }^{11-13}$ 
Recurrent disease occurs within 10 years in approximately one third of patients who have an RP. ${ }^{14-16}$ Recurrence risk is greatest among men with adverse pathological features such as positive surgical margins, seminal vesicle invasion, extraprostatic extension, and higher Gleason scores. ${ }^{17}$ There are established descriptions for adjuvant radiotherapy (ART) and salvage radiotherapy (SRT) post-prostatectomy. ART is given to patients with an undetectable PSA at high risk of recurrence because of adverse pathological features. Whereas SRT is given to patients with biochemical recurrence, defined as PSA $\geq 0.2 \mathrm{ng} / \mathrm{mL}$ with a second confirmatory level of $>0.2 \mathrm{ng} / \mathrm{mL}$, but with no evidence of distant metastatic disease. ${ }^{18}$

Three randomized trials have addressed the significance of ART, demonstrating a near $20 \%$ absolute benefit for biochemical progression-free survival at 5 years after ART compared with a "wait and see" policy for patients with pT3 \pm involved surgical margins. ${ }^{19-21}$ Systematic reviews ${ }^{22-25}$ have confirmed the benefit of ART. There are no randomized prospective studies available to prove the benefit of SRT for biochemical progression-free survival, local or systemic failure, or survival. However, observational studies using multivariate analyses have identified factors predictive of PSA recurrence and disease outcome. ${ }^{26-30}$

The definitive answer as to whether immediate adjuvant treatment is superior to early SRT is currently unknown, but is being evaluated in prospective randomized trials. These trials include the international Medical Research Council RADICALS trial (NCT00541047) ${ }^{31}$ where patients can be randomized to either early postoperative radiotherapy or deferred radiotherapy given at the time of biochemical failure. This is defined as either two consecutive rising PSA levels and a PSA $>0.1 \mathrm{ng} / \mathrm{mL}$ or three consecutive rising PSA levels. In the RAVES study (NCT00860652) ) $^{32}$ led by the TransTasman Radiation Oncology Group, patients with adverse prognostic factors were randomized to either receive ART or early SRT triggered by PSA rising to $>0.2 \mathrm{ng} / \mathrm{mL}$. A further trial, currently recruiting in France (NCT00667069), is randomizing patients to receive either immediate ART or delayed radiotherapy until biochemical relapse (defined as PSA $>0.2 \mathrm{ng} / \mathrm{mL}$ but $\leq 2 \mathrm{ng} / \mathrm{mL}$ ), with both arms receiving 6 months of triptorelin, a luteinizing hormone releasing hormone analog.

Although the clinical indications for radiotherapy post prostatectomy are becoming established, there are many aspects of post-prostatectomy radiotherapy where evidence needs to be considered and consensus gained. In this review, we consider how to define the post-prostatectomy clinical target volume (CTV) and evidence to guide the selection of appropriate dose, radiotherapy planning, and delivery techniques.

\section{Post-prostatectomy clinical target volume}

To determine the optimal CTV, it is important to appreciate the most common sites of local relapse post-prostatectomy. Nearly two thirds of local relapses identified on imaging and/ or biopsy occur at the vesicourethral anastomosis, with the bladder neck and retrotrigone area making up the significant remainder. ${ }^{33-35} \mathrm{~A}$ recent study using 1.5 or 3 Tesla (T) MRI scans from 113 patients with local recurrence assessed the locations of their recurrences to suggest an optimal target volume. ${ }^{36}$ The CTV proposal included $97 \%$ of suspected tumor recurrences, which were found at the anastomotic site (78.8\%), bladder neck (15.3\%), and retrovesical area (5.9\%). In the cranial direction, $106(87.3 \%)$ lesions were located within $3 \mathrm{~cm}$ of the inferior border of the pubic symphysis, with $12(10.2 \%)$ lesions located below this anatomical point. In the transverse plane, 112 lesions $(94.9 \%)$ were located within $10 \mathrm{~mm}$ of the midline.

During the last decade, MRI has become commonly used in the planning of prostate radiotherapy, and compared with planning CT provides improved soft tissue resolution, allowing more consistent delineation of the prostate apex, anterior rectal wall, ${ }^{37}$ and penile bulb. ${ }^{38}$ These last two structures are also important when outlining the prostate bed. Additionally, identification of the vesicourethral anastomosis is better on T2-weighted MRI sagittal slices, where it is recognized as the disruption in the high signal of urine immediately below the urethral sphincter. ${ }^{39}$

Choline positron emission tomography (PET) has been evaluated in patients with biochemical recurrence postprostatectomy. ${ }^{40-42}$ In a study comparing multi-parametric MRI (mp-MRI) at $3 \mathrm{~T}$ with endorectal coil (EC) and ${ }^{18} \mathrm{~F}$-choline PET/CT for detecting local recurrence after RP, 84 patients were allocated into two groups dependent on PSA and maximal transverse dimension of local recurrence. ${ }^{43}$ The superiority of mp-MRI was greater in group A (lesion size range 5-7.2 mm; PSA level range $0.8-1.4 \mathrm{ng} / \mathrm{mL}$ ) than in group B (lesion size range 7.6-19.4 mm; PSA level range $1.3-2.5 \mathrm{ng} / \mathrm{mL}$ ); the areas under the receiver operating characteristic curves for mp-MRI and PET/CT were 0.833 and 0.562 in group A and 0.971 and 0.837 in group B, respectively.

CTV definition in the postoperative setting is complicated due to changes in anatomy caused by surgery and the limited information on the preoperative location of the prostate. 
The pelvic anatomy after robotic-assisted RP has been shown to be considerably different from that after open prostatectomy, with the size of the trigonal musculature defect being more pronounced, total urethral length statistically longer, and larger separation for the vesicorectal distance after robotic-assisted RP. ${ }^{44}$

Substantial interphysician variation in CTV delineation for post-prostatectomy radiotherapy exists, but this can be reduced by use of a contouring protocol. ${ }^{45}$ To date, four consensus articles have been published, ${ }^{39,46-48}$ and Table 1 summarizes their guidelines on CTV delineation. A comparison of these guidelines found that treatment volumes differed significantly between guidelines and that the European Organisation for Research and Treatment of Cancer (EORTC) volume was significantly smaller than the other guideline-produced target volumes. ${ }^{49}$

\section{Use of multi-parametric MRI in CTV delineation}

These consensus guidelines have been assessed in relation to the preoperative MRI contour of the prostate and gross visible tumor. CTVs according to the four consensus guidelines were applied and expanded to create a planning target volume (PTV). ${ }^{50}$ Irrespective of the guideline used, the consensus CTVs did not completely cover the pre-resection extent of the prostate seen on the MRI in any of the 20 patients evaluated. On average, $38 \%$ of the prostate volume and $41 \%$ of the gross tumor volume (GTV) on preoperative MRI were not included in the CTV. The Radiation Therapy Oncology Group (RTOG) and Princess Margaret Hospital guidelines are similar with respect to prostate and tumor coverage and yielded the best overall results. The EORTC guidelines provided the least overall coverage. The prostate base and mid zones were the predominant site of inadequate coverage.

A further appraisal by the same group compared a CTV based upon each patient's co-registered preoperative MRI and a CTV produced using RTOG guidelines, with respect to target volumes and doses to the rectum and bladder. ${ }^{51}$ The CTV produced using the preoperative MRI volume was a mean $18.6 \%$ larger than the CTV produced using the RTOG guidelines. The mean Jaccard Index, representing the intersection volume between CTVs, was 0.72 and 0.84 for PTVs, with both methods achieving similar rectal and bladder constraints as defined by the MRC RADICALS trial ${ }^{31}$ and QUANTEC criteria. ${ }^{52}$

In post-prostatectomy patients, mp-MRI has been shown to be an effective tool for evaluation of the prostatic fossa, with the addition of dynamic contrast-enhanced MRI improving the diagnostic performance in detecting local recurrence. ${ }^{53,54}$ However, these studies were conducted with a 1.5 T MRI scanner using an EC. MRI with EC causes a distortion of local anatomy and does not allow image fusion with the radiotherapy planning CT. A study assessing dynamic contrast-enhanced MRI scans acquired on $1.5 \mathrm{~T}$ system without EC has shown that it can detect local recurrence with an estimated accuracy of $83 \%$ at low PSA levels (mean $0.74 \pm 0.64 \mathrm{ng} / \mathrm{mL}$ ).

A pre-radiotherapy PSA cut-off value of $\geq 0.54 \mathrm{ng} / \mathrm{mL}$ predicted a positive result on dynamic contrast-enhanced MRI. ${ }^{55}$ This has been further supported by a recent trial using 3 T MRI without EC, which showed that the probability of radiographic local recurrence was significantly higher in patients with PSA $>0.5 \mathrm{ng} / \mathrm{mL} .{ }^{56}$ However, these are retrospective studies, and no histopathological confirmation was undertaken to confirm the interpretation of the mp-MRI findings. Additionally, to our knowledge, there are no comparative studies evaluating the value of increasing the field strength of the magnet and using an EC in detecting local recurrence. Barchetti and Panebianco have published a thorough appraisal of the data regarding mp-MRI in identification of local recurrence after RP. ${ }^{57}$ The further development of MRI and more widespread utilization of higher strength magnets may improve the precision of localization of recurrence and comprehensive studies are awaited with interest.

\section{Boost to GTV}

The finding of local relapse on mp-MRI enables a GTV to be defined and this has enabled a dose-adapted approach to treating the prostate bed with a boost to the GTV. ${ }^{58}$

The principle of a boost to the dominant nodule in radical prostate radiotherapy has been evaluated, and mp-MRI for SRT planning purposes has the potential to identify the suspected residual disease or locoregional recurrence. The ability to boost the suspected site of relapse has been evaluated in a retrospective study where patients received a boost of $10 \mathrm{~Gy}$, with a median dose of 64 Gy to the prostatic bed. Boost and grade $\geq 2$ acute genitourinary (GU) toxicity were independently correlated with late grade $\geq 2$ GU toxicity on multivariate analysis. However, no significant difference in 3-year biochemical recurrence-free survival was observed between the boost and no-boost groups. ${ }^{59}$

Low dose rate brachytherapy in the salvage treatment of local recurrence after RP has been shown to be technically feasible, either as single modality treatment ${ }^{60}$ or to deliver a boost to the macroscopic disease within the prostate 
Table I Summary of the four consensus guidelines and guidance from the RADICALS trial for post-prostatectomy target delineation

\begin{tabular}{|c|c|c|c|}
\hline Guideline & Inferior & Superior & Lateral \\
\hline $\begin{array}{l}\text { Princess Margaret Hospital } \\
\text { Wiltshire et } \mathrm{al}^{39}\end{array}$ & $\begin{array}{l}8 \mathrm{~mm} \text { below the VUA or } \\
\text { the top of the PB, whichever } \\
\text { is most superior }\end{array}$ & $\begin{array}{l}\text { Superior surgical clips if present, or } 5 \mathrm{~mm} \\
\text { above the inferior border of the vas deferens. } \\
\text { Retained SV included when pathologically } \\
\text { involved }\end{array}$ & $\begin{array}{l}\text { Caudal: medial border } \\
\text { of the levator ani and } \\
\text { obturator internus. } \\
\text { Cranial: Sacrorecto- } \\
\text { genitopubic fascia }\end{array}$ \\
\hline $\begin{array}{l}\text { Australian and New Zealand } \\
\text { Radiation Oncology } \\
\text { Genito-Urology Group } \\
\text { Sidhom et al }{ }^{46}\end{array}$ & $\begin{array}{l}5-6 \mathrm{~mm} \text { below the VUA, but } \\
\text { should include all surgical clips } \\
\text { inferiorly. } \\
\text { If VUA not clearly defined, then } \\
\text { slice above the PB }\end{array}$ & $\begin{array}{l}\text { Encompass all of the SV bed as defined } \\
\text { by non vascular clips and should include } \\
\text { distal portion of the vas deferens. } \\
\text { If SV pathologically involved, } \\
\text { include any residual SV }\end{array}$ & $\begin{array}{l}\text { Medial border of the } \\
\text { levator ani muscle or } \\
\text { obturator internus muscle }\end{array}$ \\
\hline $\begin{array}{l}\text { Radiation Therapy } \\
\text { Oncology Group } \\
\text { Michalski et al }{ }^{47}\end{array}$ & $\begin{array}{l}\text { 8-12 mm below VUA, may include } \\
\text { more if concern for apical margin. } \\
\text { Can extend to slice above PB if } \\
\text { VUA not well visualized }\end{array}$ & $\begin{array}{l}\text { Level of cut end of vas deferens or } 3-4 \mathrm{~cm} \\
\text { above top of symphysis. Include SV remnants } \\
\text { if pathologically involved }\end{array}$ & $\begin{array}{l}\text { Below superior edge of } \\
\text { symphysis pubis: levator ani } \\
\text { muscles, obturator internus } \\
\text { Above superior edge of } \\
\text { symphysis pubis: } \\
\text { Sacrorecto-genitopubic } \\
\text { fascia* }\end{array}$ \\
\hline $\begin{array}{l}\text { EORTC (\#identified areas of } \\
\text { greatest risk of relapse)** } \\
\text { Poortmans et } \text { al }^{48}\end{array}$ & $\begin{array}{l}\text { Apex } \#-15 \mathrm{~mm} \text { cranially } \\
\text { from the PB }+5 \mathrm{~mm} \text { in all } \\
\text { directions } * * *\end{array}$ & $\begin{array}{l}\text { Bladder neck }+5 \mathrm{~mm} \text { in all directions*** } \\
\text { Original site of the base of SV should be } \\
\text { included. If } \mathrm{SV} \text { involved, include original } \\
\text { position } \pm \text { the remnants }\end{array}$ & $\begin{array}{l}\text { Up to the neurovascular } \\
\text { bundles (if removed up to } \\
\text { the ilio-obturatic muscles) } \\
+5 \mathrm{~mm} \text { in all directions } * * *\end{array}$ \\
\hline $\begin{array}{l}\text { RADICALS guidance } \\
2007 \\
\text { Parker et } \text { al }^{31}\end{array}$ & $\begin{array}{l}5 \mathrm{~mm} \text { cranial to the } \\
\text { superior border of the PB }\end{array}$ & $\begin{array}{l}\text { If SV low risk and pathology uninvolved: } \\
\text { base of SV } \\
\text { If SV low risk and pathology involved: tips of SV } \\
\text { If SV absent, superior border determined } \\
\text { with reference to the estimated position } \\
\text { of the pre-op SV }\end{array}$ & $\begin{array}{l}\text { Medial border of obturator } \\
\text { internus and levator ani } \\
\text { muscles }\end{array}$ \\
\hline
\end{tabular}

Notes: *If there is concern that extraprostatic disease at base may extend to the obturator internus; ** supplementary 5 mm in the posterior and lateral directions in the presence of incompletely resected extracapsular nodal extension, but excluding the rectal wall; supplementary $5 \mathrm{~mm}$ in the direction of microscopically involved tumor margins as reported by the pathologist (except the rectal wall). ****except the rectal wall.

Abbreviations: CTV, clinical target volume; EORTC, European Organisation for Research and Treatment of Cancer; PTV, planning target volume; PB, penile bulb; VUA, vesicourethral anastomosis; SV, seminal vesicles; SD, standard deviation.

bed. ${ }^{61}$ High dose rate (HDR) brachytherapy with or without IMRT has also been evaluated as a treatment option for patients with local recurrence. Five patients were treated with IMRT to 45-50.4 Gy in 25-28 fractions to the prostate bed followed by two 9.5 Gy HDR brachytherapy fractions separated by $1-2$ weeks, with the remaining patient treated with HDR brachytherapy (38 Gy in four fractions over 3 days). No patients had late grade 2 GI toxicity, with one patient developing late grade 2 urinary incontinence. It must be noted, however, that the median follow-up in this study was 9 months. ${ }^{62}$ These studies do demonstrate the potential use of brachytherapy for biopsy, ultrasound, or MRI-proven local recurrence; however, they are single-center experiences. With improving diagnostic capabilities for local recurrence and MRI-ultrasound fusion brachytherapy techniques, comprehensive studies with brachytherapy in the salvage setting should be undertaken with long-term effectiveness, toxicity, and quality of life endpoints.

\section{Radiotherapy dose and toxicity Dose escalation}

Among observational studies, radiotherapy doses ranged from 50 to 78 Gy, with SRT doses being somewhat higher than for ART. ${ }^{63}$ Although radiotherapy dose escalation improves freedom from biochemical recurrence (BCR) in radical prostate radiotherapy, ${ }^{64}$ the optimal post-prostatectomy dose has not yet been determined from a randomized trial. The predominant treatment failure site in patients postprostatectomy is local. ${ }^{65}$ The American Society for Radiation Oncology and American Urological Association panel view is that $64-65$ Gy is the minimum dose that should be delivered post-prostatectomy, but decisions regarding dose should be made by the treating physician. ${ }^{17}$ 


\begin{tabular}{|c|c|c|c|}
\hline Anterior & Posterior & $\begin{array}{l}\operatorname{CTV}^{49}\left(\mathrm{~cm}^{3}\right) \\
\text { mean } \pm \mathrm{SD}\end{array}$ & $\begin{array}{l}\text { PTV }^{49} \\
\left(\mathrm{~cm}^{3}\right) \\
\text { mean } \pm \mathrm{S}\end{array}$ \\
\hline $\begin{array}{l}\text { Lower border of CTV to } 3 \mathrm{~cm} \text { superior, } \\
\text { posterior aspect of the symphysis pubis } \\
\text { More superiorly: posterior } 1.5 \mathrm{~cm} \text { of the } \\
\text { bladder }\end{array}$ & $\begin{array}{l}\text { Levator ani and anterior rectal wall. More } \\
\text { superiorly, anterior mesorectal fascia }\end{array}$ & $88 \pm 16$ & $325 \pm 32$ \\
\hline $\begin{array}{l}\text { Below superior edge of symphysis pubis: } \\
\text { posterior edge of pubic bone }\end{array}$ & $\begin{array}{l}\text { Below superior edge of symphysis pubis: Anterior } \\
\text { rectal wall }\end{array}$ & $102 \pm 24$ & $35 I \pm 46$ \\
\hline $\begin{array}{l}\text { Above superior edge of symphysis pubis: } \\
\text { posterior } \mathrm{I}-2 \mathrm{~cm} \text { of bladder wall }\end{array}$ & $\begin{array}{l}\text { Above superior edge of symphysis pubis: } \\
\text { Mesorectal fascia }\end{array}$ & & \\
\hline $\begin{array}{l}\text { Anastomosis and urethral axis }+5 \mathrm{~mm} \text { in } \\
\text { all directions } * * *\end{array}$ & $\begin{array}{l}\text { Up to but not including the outer rectal wall, } \\
\text { cranially including the most posterior part of the } \\
\text { bladder neck }+5 \mathrm{~mm} \text { in all directions*** }\end{array}$ & $60 \pm 17$ & $254 \pm 53$ \\
\hline $\begin{array}{l}\text { Caudal (less than } 2 \mathrm{~cm} \text { above anastomosis): } \\
\text { posterior aspect of symphysis pubis } \\
\text { Cranial (more than } 2 \mathrm{~cm} \text { above anastomosis): } \\
\text { posterior one third of bladder wall }\end{array}$ & Anterior rectal wall & & \\
\hline
\end{tabular}

Despite early ART at a standard dose of 60-64 Gy in 2 Gy per fraction, $20.9 \%-34.9 \%$ of patients showed BCR during follow-up. ${ }^{19-21}$ In a retrospective cohort, around $75 \%$ of patients received a dose $>66$ Gy and BCR was seen at a median of 26.4 months in $19.7 \%$ of patients. Univariate analysis showed that $\mathrm{T} 4$ tumor stage, a preoperative PSA value $>10 \mathrm{ng} / \mathrm{mL}$, and a radiotherapy dose $<70$ Gy were significant factors for BCR. ${ }^{66}$ Cozzarini et al undertook a retrospective analysis where patients were grouped according to dose delivered to the prostate bed, ie, $<70.2 \mathrm{~Gy}$ (median $66.6 \mathrm{~Gy}$ ) or $\geq 70.2 \mathrm{~Gy}$ (median $70.2 \mathrm{~Gy}$ in $1.8 \mathrm{~Gy}$ fractions). Multivariate analysis confirmed that a dose $\geq 70.2$ Gy was independently related to both BCR-free survival and diseasefree survival, with similar results obtained after exclusion of patients receiving any androgen deprivation. ${ }^{67}$

A further analysis evaluated the association between SRT dose and $\mathrm{BCR}$, and their results suggested a dose response, with doses higher than 66.6 Gy resulting in decreased risk of BCR. ${ }^{68}$

Following SRT, reported 5-year biochemical control rates range from $25 \%$ to $70 \%{ }^{69}$ Retrospective analyses have identified a number of factors that may influence the efficacy of SRT, including dose..$^{70,71}$ A systematic review by King $^{72}$ included 41 published SRT studies, with a median dose of $64.6 \pm 3.1 \mathrm{~Gy}$ (range 60-74.8 Gy). There was a significant association between dose and relapse-free survival (rho $=0.42, P=0.0052$ ), with an observed improvement in relapse-free survival of $2 \%$ for each incremental Gy of dose.

A systematic review and regression meta-analysis from 25 studies including 3,828 patients, generated tumor control probability and normal tissue complication probability models. ${ }^{69}$ They estimated that with a pre-SRT PSA level of 0.4 $\mathrm{ng} / \mathrm{mL}$, an approximately $50 \%$ chance of 5 -year biochemical 
progression-free survival could be achieved with an SRT dose of 60 Gy. However, if the PSA level before SRT was $1.0 \mathrm{ng} /$ $\mathrm{mL}$, a dose of approximately 70 Gy was required to achieve similar disease control, with severe late toxicity rates at that dose potentially reaching $10 \%$. There are many confounding factors, including the use of hormonal therapy and a variety of treatment planning and delivery techniques, that preclude high quality evidence level guidance to be drawn.

A randomized Phase III trial (SAKK 09/10) for SRT is currently recruiting, where patients are randomized to either receive 64 Gy or $70 \mathrm{~Gy}^{73}$ The target volume delineation is to be performed according to EORTC guidelines and patients are excluded if they have macroscopic local recurrence.

\section{Hypofractionation}

Radiobiological studies have suggested that the estimated $\alpha / \beta$ ratio of prostate carcinoma is lower than for most other solid tumors, and around 1.5-3 Gy. ${ }^{74-77}$ Hypofractionated regimens may therefore give tumor control advantages over the more traditional 2 Gy per fraction schedules. This has been investigated internationally in several large Phase III trials in radical prostate radiotherapy. ${ }^{78-80} \mathrm{~A}$ few studies have considered this in post-prostatectomy radiotherapy, ${ }^{81-86}$ and Table 2 summarizes these data. However, most of these studies have only reported on acute toxicity, and hypofractionation does pose an increased risk for late toxicity as the fraction size and total dose increases. A recent retrospective analysis to assess predictors of severe (grade $\geq 3$ ) late urinary toxicities after post-prostatectomy radiotherapy with conventional (1.8 Gy per fraction) and hypofractionated (median 2.5 Gy per fraction) radiotherapy found on multivariate analyses, acute grade $\geq 2$ toxicity and hypofractionation to independently predict late grade $\geq 3$ toxicity. This was in both the adjuvant and salvage settings, with different radiotherapy techniques and non-standardized reporting of toxicity. ${ }^{87}$

\section{Toxicity}

GU toxicity remains the dose-limiting adverse effect of postoperative radiotherapy, even when delivered with IMRT techniques. IMRT has been shown to have no impact on late

Table 2 Comparison of acute toxicity for hypofractionated and conventionally fractionated post-prostatectomy radiotherapy

\begin{tabular}{|c|c|c|c|c|c|c|c|}
\hline Reference & Patients (n) & Trial design & $\begin{array}{l}\text { Total dose/single } \\
\text { dose fractionation } \\
\text { (EQD2) }\end{array}$ & Treatment technique & $\begin{array}{l}\text { Acute GI } \\
\text { toxicity (\%) }\end{array}$ & $\begin{array}{l}\text { Acute GU } \\
\text { toxicity (\%) }\end{array}$ & $\begin{array}{l}\text { Scoring } \\
\text { system }\end{array}$ \\
\hline \multicolumn{8}{|c|}{ Conventionally fractionated post-prostatectomy radiotherapy } \\
\hline $\begin{array}{l}\text { De Meerleer } \\
\text { et } \mathrm{al}^{27}\end{array}$ & 135 & Retrospective & Median 75 Gy/2 Gy & IMRT, regular IGRT & $\begin{array}{l}\text { G2: } 15 \\
\text { G3: } 0\end{array}$ & $\begin{array}{l}\text { G2: } 28 \\
\text { G3: } 3\end{array}$ & In-house \\
\hline $\begin{array}{l}\text { Cozzarini } \\
\text { et al }{ }^{67}\end{array}$ & $\begin{array}{l}153 \\
181\end{array}$ & Retrospective & $\begin{array}{l}\text { Median } 66.6 \mathrm{~Gy} / \mathrm{l} .8 \mathrm{~Gy} \\
\text { Median } \\
70.2 \mathrm{~Gy} / \mathrm{l} .8 \mathrm{~Gy}\end{array}$ & $\begin{array}{l}\text { Conventional non- } \\
\text { conformal, 3D-CRT }\end{array}$ & $\begin{array}{l}\text { G2/3: } 17.5 \\
G 2 / 3: 14\end{array}$ & $\begin{array}{l}\text { G2: } 10.5 \\
\text { G3: } 4 \\
\text { G2: II.5 } \\
\text { G3: } 2\end{array}$ & RTOG \\
\hline Nath et $\mathrm{a}^{89}$ & 50 & Retrospective & Median 68 Gy/l.8-2 Gy & IMRT, daily IGRT & $\begin{array}{l}\text { G2: } 8 \\
\text { G3: } 0\end{array}$ & $\begin{array}{l}\text { G2: } 14 \\
\text { G3: } 0\end{array}$ & $\begin{array}{l}\mathrm{NCI} C \mathrm{CTCAE} \\
\text { v. } 3.0\end{array}$ \\
\hline Riou et al ${ }^{90}$ & 57 & Retrospective & Mean 68 Gy/2 Gy & IMRT, IGRT & $\begin{array}{l}\text { G2: } 4 \\
\text { G3: } 0\end{array}$ & $\begin{array}{l}\mathrm{G} 2: 7 \\
\mathrm{G} 3: 0\end{array}$ & $\begin{array}{l}\mathrm{NCI} C \mathrm{CTCAE} \\
\text { v. } 3.0\end{array}$ \\
\hline $\begin{array}{l}\text { Bellavita } \\
\text { et al }\end{array}$ & 182 & Retrospective & $\begin{array}{l}\text { Median } 66.6 \mathrm{~Gy} / \\
\text { I.8-2 Gy }\end{array}$ & 3D-CRT & $\begin{array}{l}\text { G2: } 39 \\
\text { G3: I }\end{array}$ & $\begin{array}{l}\text { G2: } 21 \\
\text { G3: } 0\end{array}$ & RTOG \\
\hline \multicolumn{8}{|c|}{ Hypofractionated post-prostatectomy radiotherapy } \\
\hline $\begin{array}{l}\text { Massaccesi } \\
\text { et a }\left.\right|^{81}\end{array}$ & 49 & $\begin{array}{l}\text { Prospective, non- } \\
\text { randomized Phase II }\end{array}$ & $\begin{array}{l}62.5 \mathrm{~Gy} / 2.5 \mathrm{~Gy} \\
(71.4 \mathrm{~Gy})\end{array}$ & SIB-IMRT & $\begin{array}{l}\text { G2: } 32.6 \\
\text { G3: } 0\end{array}$ & $\begin{array}{l}\text { G2: } 9.6 \\
\text { G3: } 0\end{array}$ & RTOG \\
\hline $\begin{array}{l}\text { Cozzarini } \\
\text { et al }{ }^{83}\end{array}$ & 50 & $\begin{array}{l}\text { Prospective, non- } \\
\text { randomized } \\
\text { Phase I/II }\end{array}$ & $\begin{array}{l}58 \mathrm{~Gy} / 2.9 \mathrm{~Gy} \\
(72.9 \mathrm{~Gy})\end{array}$ & Tomotherapy, daily IGRT & $\begin{array}{l}\text { G2: } 4 \\
\text { G3: } 0\end{array}$ & $\begin{array}{l}\text { G2: } 10 \\
\text { G3: } 2\end{array}$ & RTOG \\
\hline $\begin{array}{l}\text { Kruser } \\
\text { et a }{ }^{84}\end{array}$ & 108 & Retrospective & 65 Gy/2.5 Gy (74.3 Gy) & $\begin{array}{l}\text { Tomotherapy, daily IGRT, } \\
\text { endorectal balloon }\end{array}$ & $\begin{array}{l}\text { G2: } 14 \\
\text { G3: } 0\end{array}$ & $\begin{array}{l}\text { G2: } 7 \\
\text { G3: I }\end{array}$ & $\begin{array}{l}\text { Modified } \\
\text { RTOG }\end{array}$ \\
\hline $\begin{array}{l}\text { Katayama } \\
\text { et a }\left.\right|^{85}\end{array}$ & 39 & $\begin{array}{l}\text { Prospective, non- } \\
\text { randomized Phase II }\end{array}$ & 54 Gy/3 Gy (69.4 Gy) & Tomotherapy, daily IGRT & $\begin{array}{l}\text { G2: } 18 \\
\text { G3: } 0\end{array}$ & $\begin{array}{l}\text { G2: } 0 \\
\text { G3: } 0\end{array}$ & $\begin{array}{l}\mathrm{NCI} C \mathrm{CTCAE} \\
\text { v. } 4.0\end{array}$ \\
\hline $\begin{array}{l}\text { Gladwish } \\
\text { et } \mathrm{al}^{86}\end{array}$ & 30 & $\begin{array}{l}\text { Prospective, non- } \\
\text { randomized } \\
\text { Phase I/II }\end{array}$ & $\begin{array}{l}5 \text { I Gy/3 Gy } \\
\text { (65.6 Gy) }\end{array}$ & $\begin{array}{l}\text { IMRT, daily IGRT } \\
\text { (fiducial-based) }\end{array}$ & $\begin{array}{l}\text { G2: } 0 \\
\text { G3: } 0\end{array}$ & $\begin{array}{l}\text { G2: } 3 \\
\text { G3: } 3\end{array}$ & $\begin{array}{l}\mathrm{NCI} C \mathrm{CTCAE} \\
\text { v. } 3.0\end{array}$ \\
\hline
\end{tabular}

Note: EQD2, 2 Gy-equivalent dose (assumed $\alpha / \beta$ ratio of 1.5 Gy).

Abbreviations: GI, gastrointestinal; GU, genitourinary; IGRT, image-guided radiotherapy; IMRT, intensity modulated radiotherapy; NCI CTCAE, National Cancer Institute Common Terminology Criteria for Adverse Events; RTOG, Radiation Therapy Oncology Group; 3D-CRT, three-dimensional conformal radiotherapy; SIB-IMRT, simultaneous integrated boost intensity modulated radiotherapy; G, grade. 
urinary toxicity compared with 3D-CRT in patients treated at the same dose and to the same volume definition. ${ }^{88}$

A few retrospective studies have investigated the use of IMRT for post-prostatectomy radiotherapy. ${ }^{27,89,90}$ Bastasch et $\mathrm{al}^{91}$ reported the effects on erectile function of doseescalated prostate bed IMRT in a retrospective series. Despite the high dose (mean 69.6 Gy) to the prostate bed, this had no negative effect on erectile function for the patients who remained potent after nerve-sparing prostatectomy; the follow-up in this group was 19.5 months.

Ost et $\mathrm{al}^{92}$ reported the clinical results of adjuvant IMRT (median dose to PTV: 74 Gy in 2 Gy per fraction) in 104 patients. With respect to acute and late toxicity, no patients developed grade 3 GI toxicity, with $8 \%$ and $4 \%$ of patients developing acute and late grade $3 \mathrm{GU}$ toxicity respectively.

Toxicity with dose escalation in SRT has been retrospectively evaluated, and with a median dose of 70.2 Gy, grade $3 / 4$ late GU and GI toxicity was $29.6 \%$ and $5.6 \%$, respectively. There was a non-significant trend towards reduced late GI toxicity with IMRT. ${ }^{93}$

IMRT creates an opportunity to reduce side effects or attempt dose escalation to increase the probability of tumor control. A Phase II trial has recently been published, where patients who received 66Gy in $2 \mathrm{~Gy}$ dose per fraction with IMRT were evaluated with health-related quality of life outcomes. ${ }^{94}$ Expanded Prostate Cancer Index Composite (EPIC) scores were collected prospectively and showed transient declines in the EPIC GI domain summary score and GU irritative subscale, with complete recovery occurring between 3 and 12 months after radiotherapy, and remaining stable compared with baseline at 5-year follow-up. Sexual health-related quality of life remained stable at 5 years, with an improving trend in bother subscale.

At the Memorial Sloan-Kettering Cancer Center, a retrospective analysis of late toxicity (5-year actuarial rates) was undertaken of patients predominantly treated with either 3D-CRT or IMRT to a dose of $\geq 70$ Gy with a median follow-up of 60 months. ${ }^{95}$ Two hundred and five patients ( $72 \%$ ) were treated with doses $\geq 70$ Gy. IMRT was independently associated with a reduction in late grade $\geq 2$ GI toxicity compared with 3D-CRT (1.9\% versus $10.2 \%$, respectively; $P=0.02$ ), despite the fact that those patients treated with IMRT were more likely to be treated with a higher dose than those receiving 3D-CRT. This supports the idea that IMRT improves the therapeutic ratio associated with SRT. However, IMRT was not associated with a reduction in risk of grade $\geq 2$ GU toxicity, urinary incontinence, or grade 3 erectile dysfunction.

\section{Radiotherapy planning technique}

The CTV has an irregular shape, with its borders associated with the rectum and bladder, making it particularly difficult to sculpt the dose away from the organs at risk (OAR). Koontz et al $^{96}$ demonstrated that IMRT provides better highdose sparing of the OAR than 3D-CRT. In addition, Cozzarini et $\mathrm{al}^{83}$ demonstrated a benefit for helical tomotherapy compared with 3D-CRT with regards to rectal sparing.

As previously discussed, there is no clear consensus regarding CTV delineation for postoperative prostate radiotherapy. Analysis of dose volume histograms (DVH) was performed with the four published guidelines for CTV delineation ${ }^{39,46-48}$ and the dose constraints proposed in QUANTEC ${ }^{52}$ and the RADICALS ${ }^{31}$ trial. Comparison between 3D-CRT and tomotherapy IMRT showed that the latter reduced OAR irradiation; however, despite using IMRT, a significant percentage of cases did not meet the OAR dose constraints. ${ }^{49}$ There is currently no agreement regarding the superiority of advanced forms of external beam radiotherapy.

A radiotherapy quality assurance program undertaken as part of the SAKK 09/10 trial had $43 \%$ of the centers using 3D-CRT, with the remaining centers using IMRT or volumetric modulated arc therapy (VMAT). CTVs were outlined using the EORTC guidelines, and the rectal and bladder wall DVH parameters with IMRT or VMAT versus 3D-CRT plans were not significantly different. ${ }^{73}$ A study quantifying the differences in treatment delivery efficiency and dosimetry between step and shoot IMRT, VMAT, and helical tomotherapy has shown that VMAT improves the efficiency of delivery for equivalent dosimetric quality compared with IMRT and helical tomotherapy in prostate bed \pm whole pelvis radiotherapy. ${ }^{97}$

\section{Image-guided radiotherapy}

Variation in location of the prostate bed is significantly influenced by the changing shape and volume of the rectum and bladder during treatment. Rectal volumes can vary significantly throughout treatment from $-40 \%$ to $+60 \%$ compared with planning, with bladder volumes fluctuating up to $200 \mathrm{~cm}^{3} .^{98}$ These day-to-day fluctuations can have a substantial dosimetric effect on both the prostate bed and OAR. ${ }^{99}$ The greatest potential for geographical miss has been seen when either the bladder increases in size or the rectum becomes smaller. ${ }^{100}$ Uncertainties due to patient set-up errors and prostate bed motion ${ }^{101}$ require a margin around the CTV to create the PTV. Minimizing these uncertainties can facilitate smaller CTV to PTV margins, thereby reducing the dose to OAR. 
The accuracy of bony anatomy as a surrogate for prostate bed position is inadequate to account for intrafraction motion. Relative to bony anatomy, prostate bed displacement exceeded $5 \mathrm{~mm}$ in $21 \%$ of treatments of 20 patients in the superiorinferior direction and $9 \%$ in the anterior-posterior position. During treatment, the target exceeded the $5 \mathrm{~mm}$ tracking limit for at least 30 seconds in $11 \%$ of all fractions, generally in the anterior-posterior or superior-inferior direction. In the anterior-posterior direction, target motion was more likely to move posteriorly towards the rectum than anteriorly. ${ }^{102}$

A predominant source of intrafraction error is prostate bed motion, and there is an interest in determining the best treatment margin to account for daily set-up uncertainty and prostate bed motion. There is a lack of data regarding the best treatment margin to account for daily set-up uncertainty and organ motion. Surgical clips have been used as fiducial markers for the prostate bed, with their positional shifts captured and recorded by $\mathrm{kV}$ images. ${ }^{103,104}$ However, surgical clips have often been found to be positioned outside the prostate bed, poorly visualized, and closely clustered. ${ }^{105}$

Implantation of gold seeds ${ }^{106}$ and electromagnetic transponders ${ }^{107}$ into the prostate bed has been described and data regarding prostate bed motion published..$^{102,108,109}$ The stability and interobserver variability of fiducial markers and position of surgical clips in the prostate bed has been considered, and fiducial markers were seen to give less interobserver variability in matching and less variation in position than surgical clips. ${ }^{105}$ The largest discrepancy in matching between surgical clips and fiducial markers was in the anterior-posterior axis. Migration of gold seed fiducials over a course of radiotherapy has been shown to be minimal, with the mean measured differences in inter-marker distance between the start and end of radiotherapy being $0.4 \mathrm{~mm} .{ }^{110}$ However, implantation of the fiducial markers is an invasive procedure with associated morbidity. ${ }^{106}$

Table 3 summarizes the findings from studies evaluating interfraction prostate bed motion, which is defined as the change in position of the prostate bed in relation to pelvic bony anatomy. There has been a suggestion from the data that an anisotropic PTV margin should be used in post-prostatectomy radiotherapy. ${ }^{111} \mathrm{~A}$ differential superior and inferior prostate bed motion has been reported, with the greatest movement occurring in the anterior-posterior plane in the upper prostate bed; however, in this study, only one surgical clip in the superior and in the inferior section was selected. The variability in movement between these clips implies that prostate bed tilt is a factor in interfraction motion and may not be easily corrected for with standard online matching techniques.

Significant intrafraction prostate bed motion and deformation has been found, as the boundaries are largely defined by the interfaces of the bladder and rectum, which are influenced by intrafractional variations in filling. Diot et $\mathrm{a}^{112}$ performed a study analyzing the effects of anatomical interventions, such as adjusting bladder filling, evacuation of stool, or insertion of a rubber catheter into the rectum to deal with excess gas. The indications for these interventions were determined on sagittal images when the anterior rectal wall displacement was greater than $5 \mathrm{~mm}$ or by a change in volume of the bladder by a factor of 2 compared with the planning CT. The comparison of pre and post intervention localization suggests that fluctuations in the volume and

Table 3 Interfraction prostate bed motion and calculated margins based on interfraction motion

\begin{tabular}{|c|c|c|c|c|c|}
\hline Reference & $\begin{array}{l}\text { Patients/images } \\
\text { IGRT method }\end{array}$ & Interfraction РВМ & $\begin{array}{l}\text { Lateral } \\
\mathbf{m m}(\mathrm{SD})\end{array}$ & $\begin{array}{l}\text { Superior-inferior } \\
\mathbf{m m}(\mathrm{SD})\end{array}$ & $\begin{array}{l}\text { Anterior-posterior } \\
\mathrm{mm} \text { (SD) }\end{array}$ \\
\hline $\begin{array}{l}\text { Schiffner } \\
\text { et al } 110\end{array}$ & $\begin{array}{l}\text { 10/163 } \\
\text { Gold seeds, EPID }\end{array}$ & Mean: & $0.3(0.9)$ & $0.4(2.4)$ & $-1.1(2.1)$ \\
\hline $\begin{array}{l}\text { Sandhu } \\
\text { et al }\left.\right|^{16}\end{array}$ & $\begin{array}{l}26 / 692 \\
\text { Surgical clips, kV }\end{array}$ & Mean magnitude: & I (I.7) & $2.4(2.1)$ & $2.7(2.1)$ \\
\hline Ost et $\mathrm{al}^{115}$ & $\begin{array}{l}\text { I5/547 } \\
\text { Anterior rectal wall, CBCT }\end{array}$ & $\begin{array}{l}\text { Mean: } \\
\text { Calculated margin* }\end{array}$ & $\begin{array}{l}0.01 \\
1.78\end{array}$ & $\begin{array}{l}0.58 \\
3.27\end{array}$ & $\begin{array}{l}2.19 \\
7.88\end{array}$ \\
\hline $\begin{array}{l}\text { Huang } \\
\text { et al }{ }^{103}\end{array}$ & $\begin{array}{l}\text { I } 4 / 420 \\
\text { Surgical clips, CBCT }\end{array}$ & $\begin{array}{l}\text { Mean: } \\
\text { Calculated margin* }\end{array}$ & $\begin{array}{l}0 \\
3.24\end{array}$ & $\begin{array}{l}-0.9 \\
5.49\end{array}$ & $\begin{array}{l}1.9 \\
8.36\end{array}$ \\
\hline Bell et al'"I & $\begin{array}{l}40 / 377 \\
\text { Surgical clips, CBCT }\end{array}$ & $\begin{array}{l}\text { Mean magnitude: } \\
\text { Upper } \\
\text { Lower }\end{array}$ & $\begin{array}{l}0.1(0.12) \\
0.08(0.1)\end{array}$ & $\begin{array}{l}0.28(0.26) \\
0.18(0.17)\end{array}$ & $\begin{array}{l}0.5(0.5) \\
0.18(0.16)\end{array}$ \\
\hline $\begin{array}{l}\text { Alander } \\
\text { et al }{ }^{109}\end{array}$ & $\begin{array}{l}\text { I3/466 } \\
\text { Gold seeds, CBCT }\end{array}$ & $\begin{array}{l}\text { Mean: } \\
\text { Calculated margin** }\end{array}$ & $\begin{array}{l}0(0.5) \\
\text { I.4 }\end{array}$ & $\begin{array}{l}0.7(2.1) \\
5.9\end{array}$ & $\begin{array}{l}0.8(1.6) \\
5.9\end{array}$ \\
\hline
\end{tabular}

Notes: PBM, motion of the either the gold seeds, surgical clips, or anterior rectal wall in relation to bony pelvic anatomy and is the mean of the individual patient means, unless otherwise stated. Mean magnitude: average of absolute values of all measurements in a given plane. Margin recipe used: $* 2.5 \Sigma+0.7 \sigma ; * * 1.96 \Sigma+0.7 \sigma$.

Abbreviations: PBM, prostate bed motion; CBCT, cone-beam computed tomography; CTV, clinical target volume; PTV, planning target volume; IGRT, image-guided radiotherapy; SD, standard deviation. 
shape of the rectum and bladder increase the variability of the localization data most significantly in the anterior-posterior direction, with lesser effect in the superior-inferior direction. The dosimetric impact on performing these interventions to reduce treatment volume deformations due to bladder and rectal filling showed no significant difference for PTV coverage, or rectal or bladder sparing. However, this concept should be re-examined for hypofractionated treatments, as the gains from correcting one fraction would contribute to a larger portion of the treatment, and therefore may be more dosimetrically relevant. ${ }^{113}$ Other studies have used the anterior rectal wall as a surrogate for prostate bed motion. ${ }^{27,114-117}$

Post-prostatectomy IMRT has enabled improved toxicity profiles compared with conventional radiotherapy techniques. ${ }^{118,119}$ With the increasing use of IMRT, enabling dose escalation and the associated steep dose gradients, it is critical to accurately localize the target for precise treatment delivery. Image-guided radiotherapy (IGRT) either using soft tissue, surgical clips, fiducial markers have been applied in prostate bed radiotherapy. The associated consequences in toxicity with IGRT have been evaluated in retrospective studies using 3D-CRT or IMRT. ${ }^{89}$ Rates of acute toxicity with cone beam CT-guided conformal radiotherapy to a median dose of $68.4 \mathrm{~Gy}$ were similar to treatment to $64.8 \mathrm{~Gy}$ without image guidance radiotherapy. ${ }^{120}$

\section{Role of rectal stabilizers}

Studies using cine-MRI to assess intrafraction motion identified rectal filling as a predictor of prostate motion. ${ }^{121,122}$ A filled rectum is associated with mobile gas pockets, leading to rectal motion. Therefore, a device inserted into the rectum should minimize a change in rectal filling or gas position and hence stability of rectum and therefore prostate or prostate bed.

The use of endorectal balloons (ERBs) was first reported in prostate radiotherapy in 1979, and has been investigated regarding its potential immobilizing properties and dosimetric consequences. ${ }^{123}$ Definite conclusions from a systematic review are difficult as there were many variables between the trials; however, it was felt that as the ERB is situated directly adjacent to the anterior rectal wall and is visualized on portal imaging, it can assist in localizing the prostate and thus in reducing the CTV to PTV margins. There was a rectal and anal wall sparing effect for the intermediate and high-dose regions even with IMRT, and the dosimetric consequence on the target volume of having an air-filled balloon in the rectum has been addressed and shown not to underdose the prostate.
In the last 5 years, reports of ERBs in the post-prostatectomy setting have been published. Improvement in DVH with ERB has been seen in a planning study by Smeenk et al. ${ }^{124}$ They found significantly reduced anal wall DVH and to a lesser extent rectal DVH with the ERB. The mean dose to the anal wall was reduced by 6 Gy. However, a study assessing dosimetric stability to the CTV with ERBs did not observe any improvement, although there was improved geometric stability of the rectum. ${ }^{125}$ This observation may be due to deformation of the CTV caused by the ERB.

A recently published study by the same group compared geometric variations in CTV and OAR during prostate bed radiotherapy with and without the use of ERB. ${ }^{126}$ Cone-beam CTs were reviewed and CTV contoured and subdivided into superior and inferior CTV with the whole rectal volume subdivided into superior and inferior rectum and anal volume. The concordance index of cone beam CT treatment volumes compared with planning volumes was calculated and displacements measured. Rectal stability was improved with the use of ERB (concordance index improvement from 0.41 to 0.71 ), which translated into greater CTV stability with the improved concordance index in the ERB group. However, displacements of the center of volumes (centroids) for the superior and inferior CTV were not significantly different between the two groups. This study also looked at bladder filling and found that the ERB negated the impact of bladder filling on CTV stability, postulating that this was due to the ERB physically compressing the bladder anteriorly against the pubic symphysis for the majority of the CTV. However, they did not report on centroid displacements in the superiorinferior direction, which may be more susceptible due to positioning interfraction variation with the ERB.

A retrospective analysis of the largest reported cohort using ERBs after RP was by Ishiyama et al. ${ }^{127}$ They reported acceptable late RTOG GI and GU toxicity, with the highest late GU toxicity being grade 2 in $13 \%$ and grade 3 in $6 \%$ of patients. The highest late GI toxicity was grade 2 in $6 \%$ and grade 3 in $3 \%$ of patients. One hundred and seven patients were assessed, and the prescribed mean dose to the CTV was 70 Gy in 32 fractions (EQD2 $=73.9$ Gy based on $\alpha / \beta=1.5$ ). However, this study has not recorded patient-reported outcomes, which may be a better measure of treatment-related toxicities than physician-reported assessments. ${ }^{128,129}$

A novel rectal obturator, ProSpare ${ }^{\mathrm{TM}}$, has been developed at the Institute of Cancer Research, London, UK, as a singleuse device made from high impact polystyrene, which is inserted by the patient just prior to radiotherapy. It has radioopaque markers encased in the anterior and posterior wall of 
the device, allowing clear identification of the anterior rectal wall. It has venting holes in the tip of the device and a venting line along the central join of the device to allow passage of rectal gas through the device and deflate any rectal gas bubbles on insertion. It has been evaluated in prostate radiotherapy and shown to be an effective minimally invasive daily online image-guided tool and rectal spacer. ${ }^{130-132}$ A Phase II trial (POPS; Post-Operative ProSpare) randomizing patients to receive post-prostatectomy IMRT with or without ProSpare will start recruiting in the UK by the end of 2015 .

\section{Conclusion}

Despite the publication of four guidelines, there is a lack of consensus on CTV definition. Information from imaging such as mp-MRI should be considered when defining the CTV and incorporated into the contouring guidelines, to enable a personalized approach to an optimal target volume. It is unclear whether a differential dose in ART and SRT is needed to improve biochemical failure-free survival and whether this translates into an overall survival benefit. The long-term efficacy and tolerability data for hypofractionated schedules are not yet established.

IMRT and IGRT enable dose escalation to the target volume and permit delivery of a simultaneous integrated boost to a GTV; randomized trials are needed to determine if there is a clinical outcome benefit with acceptable toxicity. More data in larger patient groups on IGRT post-prostatectomy and prostate bed motion are needed before CTV-to-PTV margins can be modified. Rectal stabilizing methods are available and should be considered, as this may result in a reduction in prostate bed deformation and motion during treatment.

Toxicity with dose escalation and IMRT techniques appears acceptable, although GU toxicity remains the doselimiting factor. Increased knowledge of the dose-response relationship is needed regarding OAR or specific regions within these organs associated with GU toxicity.

As the current randomized controlled trials mature, we shall have better information to determine the indications for radiotherapy and its timing and the need for androgen deprivation therapy. However, challenges remain to providing the evidence base to refine the definition of radiotherapy planning targets, optimal treatment planning, and delivery strategies.

\section{Acknowledgment}

We acknowledge National Health Service funding to the NIHR Biomedical Research Centre at The Royal Marsden Hospital and Institute of Cancer Research, London. JRM is supported by Cancer Research UK Clinical PhD Training Fellowship. DPD and HAM are supported by Cancer Research UK Programme Grant C33589/A19727.

\section{Disclosure}

The authors declare that there is no conflict of interests in this work.

\section{References}

1. Dearnaley DP, Sydes MR, Langley RE, et al. The early toxicity of escalated versus standard dose conformal radiotherapy with neo-adjuvant androgen suppression for patients with localised prostate cancer: results from the MRC RT01 trial (ISRCTN47772397). Radiother Oncol. 2007;83(1):31-41.

2. Peeters ST, Heemsbergen WD, Koper PC, et al. Dose-response in radiotherapy for localized prostate cancer: results of the Dutch multicenter randomized phase III trial comparing 68 Gy of radiotherapy with 78 Gy. J Clin Oncol. 2006;24(13):1990-1996.

3. Kuban DA, Tucker SL, Dong L, et al. Long-term results of the M. D. Anderson randomized dose-escalation trial for prostate cancer. Int $J$ Radiat Oncol Biol Phys. 2008;70(1):67-74.

4. Hummel S, Simpson EL, Hemingway P, Stevenson MD, Rees A. Intensity-modulated radiotherapy for the treatment of prostate cancer: a systematic review and economic evaluation. Health Technol Assess. 2010;14(47):1-108, iii-iv.

5. Dolezel M, Odrazka K, Zouhar M, et al. Comparing morbidity and cancer control after 3D-conformal (70/74 Gy) and intensity modulated radiotherapy (78/82 Gy) for prostate cancer. Strahlenther Onkol. 2015;191(4):338-346.

6. Ferlay J, Soerjomataram I, Ervik M, et al. Cancer incidence and mortality worldwide: IARC Cancer Base No 11. 2012, GLOBOCAN 2012 v1.0. Available from: http://globocan.iarc.fr. Accessed July 23, 2015.

7. Stitzenberg KB, Wong YN, Nielsen ME, Egleston BL, Uzzo RG. Trends in radical prostatectomy: centralization, robotics, and access to urologic cancer care. Cancer. 2012;118(1):54-62.

8. Etzioni R, Mucci L, Chen S, Johansson JE, Fall K, Adami HO. Increasing use of radical prostatectomy for nonlethal prostate cancer in Sweden. Clin Cancer Res. 2012;18(24):6742-6747.

9. Ohmann EL, Loeb S, Robinson D, Bill-Axelson A, Berglund A, Stattin P. Nationwide, population-based study of prostate cancer stage migration between and within clinical risk categories. Scand J Urol. 2014;48(5):426-435.

10. Fu Q, Moul JW, Sun L. Contemporary radical prostatectomy. Prostate Cancer. 2011;2011:645030.

11. Heidenreich A, Bastian PJ, Bellmunt J, et al. EAU guidelines on prostate cancer. Part 1: screening, diagnosis, and local treatment with curative intent-update 2013. Eur Urol. 2014;65(1):124-137.

12. Mohler JL, Kantoff PW, Armstrong AJ, et al. Prostate cancer, version 2.2014. J Natl Compr Canc Netw. 2014;12(5):686-718.

13. Stewart SB, Boorjian SA. Radical prostatectomy in high-risk and locally advanced prostate cancer: Mayo Clinic perspective. Urol Oncol. 2015;33(5):235-244.

14. Pound CR, Partin AW, Epstein JI, Walsh PC. Prostate-specific antigen after anatomic radical retropubic prostatectomy. Patterns of recurrence and cancer control. Urol Clin North Am. 1997;24(2):395-406.

15. Zincke H, Oesterling JE, Blute ML, Bergstralh EJ, Myers RP, Barrett DM. Long-term (15 years) results after radical prostatectomy for clinically localized (stage T2c or lower) prostate cancer. $J$ Urol. 1994;152(5 Pt 2):1850-1857.

16. Isbarn H, Wanner M, Salomon G, et al. Long-term data on the survival of patients with prostate cancer treated with radical prostatectomy in the prostate-specific antigen era. BJU Int. 2010;106(1): $37-43$. 
17. Valicenti RK, Thompson I Jr, Albertsen P, et al. Adjuvant and salvage radiation therapy after prostatectomy: American Society for Radiation Oncology/American Urological Association guidelines. Int $J$ Radiat Oncol Biol Phys. 2013;86(5):822-828.

18. Cookson MS, Aus G, Burnett AL, et al. Variation in the definition of biochemical recurrence in patients treated for localized prostate cancer: the American Urological Association Prostate Guidelines for Localized Prostate Cancer Update Panel report and recommendations for a standard in the reporting of surgical outcomes. J Urol. 2007;177(2):540-545.

19. Thompson IM, Tangen CM, Paradelo J, et al. Adjuvant radiotherapy for pathological T3N0M0 prostate cancer significantly reduces risk of metastases and improves survival: long-term followup of a randomized clinical trial. J Urol. 2009;181(3):956-962.

20. Wiegel T, Bottke D, Steiner U, et al. Phase III postoperative adjuvant radiotherapy after radical prostatectomy compared with radical prostatectomy alone in $\mathrm{pT} 3$ prostate cancer with postoperative undetectable prostate-specific antigen: ARO 96-02/AUO AP 09/95. J Clin Oncol. 2009;27(18):2924-2930.

21. Bolla M, van Poppel H, Tombal B, et al. Postoperative radiotherapy after radical prostatectomy for high-risk prostate cancer: long-term results of a randomised controlled trial (EORTC trial 22911). Lancet. 2012;380(9858):2018-2027.

22. Bartkowiak D, Bottke D, Wiegel T. Radiotherapy in the management of prostate cancer after radical prostatectomy. Future Oncol. 2013;9(5): 669-679.

23. Daly T, Hickey BE, Lehman M, Francis DP, See AM. Adjuvant radiotherapy following radical prostatectomy for prostate cancer. Cochrane Database Syst Rev. 2011;12:CD007234

24. Morgan SC, Waldron TS, Eapen L, et al. Adjuvant radiotherapy following radical prostatectomy for pathologic T3 or margin-positive prostate cancer: a systematic review and meta-analysis. Radiother Oncol. 2008;88(1):1-9.

25. Ganswindt U, Stenzl A, Bamberg M, Belka C. Adjuvant radiotherapy for patients with locally advanced prostate cancer - a new standard? Eur Urol. 2008;54(3):528-542.

26. Wiegel T, Lohm G, Bottke D, et al. Achieving an undetectable PSA after radiotherapy for biochemical progression after radical prostatectomy is an independent predictor of biochemical outcome results of a retrospective study. Int J Radiat Oncol Biol Phys. 2009;73(4):1009-1016.

27. De Meerleer G, Fonteyne V, Meersschout S, et al. Salvage intensitymodulated radiotherapy for rising PSA after radical prostatectomy. Radiother Oncol. 2008;89(2):205-213.

28. Buskirk SJ, Pisansky TM, Schild SE, et al. Salvage radiotherapy for isolated prostate specific antigen increase after radical prostatectomy: evaluation of prognostic factors and creation of a prognostic scoring system. J Urol. 2006;176(3):985-990.

29. Ost P, De Gersem W, De Potter B, Fonteyne V, De Neve W, De Meerleer G. A comparison of the acute toxicity profile between two-dimensional and three-dimensional image-guided radiotherapy for postoperative prostate cancer. Clin Oncol (R Coll Radiol). 2011;23(5):344-349.

30. Neuhof D, Hentschel T, Bischof M, Sroka-Perez G, Hohenfellner M, Debus J. Long-term results and predictive factors of three-dimensional conformal salvage radiotherapy for biochemical relapse after prostatectomy. Int J Radiat Oncol Biol Phys. 2007;67(5): 1411-1417.

31. Parker C, Sydes MR, Catton C, et al. Radiotherapy and androgen deprivation in combination after local surgery (RADICALS) a new Medical Research Council/National Cancer Institute of Canada phase III trial of adjuvant treatment after radical prostatectomy. BJU Int. 2007;99(6):1376-1379.

32. Pearse M, Fraser-Browne C, Davis ID, et al. A Phase III trial to investigate the timing of radiotherapy for prostate cancer with high-risk features: background and rationale of the Radiotherapy - Adjuvant Versus Early Salvage (RAVES) trial. BJU Int. 2014;113 Suppl $2: 7-12$.
33. Connolly JA, Shinohara K, Presti JC Jr, Carroll PR. Local recurrence after radical prostatectomy: characteristics in size, location, and relationship to prostate-specific antigen and surgical margins. Urology. 1996;47(2):225-231.

34. Sella T, Schwartz LH, Swindle PW, et al. Suspected local recurrence after radical prostatectomy: endorectal coil MR imaging. Radiology. 2004;231(2):379-385

35. Leventis AK, Shariat SF, Slawin KM. Local recurrence after radical prostatectomy: correlation of US features with prostatic fossa biopsy findings. Radiology. 2001;219(2):432-439.

36. Park JS, Park W, Pyo HR, et al. Suggestion for the prostatic fossa clinical target volume in adjuvant or salvage radiotherapy after a radical prostatectomy. Radiother Oncol. 2014;110(2):240-244.

37. Roach M 3rd, Faillace-Akazawa P, Malfatti C, Holland J, Hricak H. Prostate volumes defined by magnetic resonance imaging and computerized tomographic scans for three-dimensional conformal radiotherapy. Int J Radiat Oncol Biol Phys. 1996;35(5):1011-1018.

38. Perna L, Cozzarini C, Maggiulli E, et al. Inter-observer variability in contouring the penile bulb on CT images for prostate cancer treatment planning. Radiat Oncol. 2011;6:123.

39. Wiltshire KL, Brock KK, Haider MA, et al. Anatomic boundaries of the clinical target volume (prostate bed) after radical prostatectomy. Int J Radiat Oncol Biol Phys. 2007;69(4):1090-1099.

40. Reske SN. [11C]Choline uptake with PET/CT for the initial diagnosis of prostate cancer: relation to PSA levels, tumour stage and anti-androgenic therapy. Eur J Nucl Med Mol Imaging. 2008;35(9):1740-1741.

41. Stephenson AJ, Scardino PT, Kattan MW, et al. Predicting the outcome of salvage radiation therapy for recurrent prostate cancer after radical prostatectomy. J Clin Oncol. 2007;25(15):2035-2041.

42. Kitajima K, Murphy RC, Nathan MA, et al. Detection of recurrent prostate cancer after radical prostatectomy: comparison of $11 \mathrm{C}$-choline PET/CT with pelvic multiparametric MR imaging with endorectal coil. J Nucl Med. 2014;55(2):223-232.

43. Panebianco V, Sciarra A, Lisi D, et al. Prostate cancer: 1 HMRS-DCEMR at $3 \mathrm{~T}$ versus $[(18) \mathrm{F}]$ choline PET/CT in the detection of local prostate cancer recurrence in men with biochemical progression after radical retropubic prostatectomy (RRP). Eur J Radiol. 2012;81(4):700-708.

44. Hirsch AE, Cuaron JJ, Janicek MJ, et al. Anatomic differences after robotic-assisted radical prostatectomy and open prostatectomy: implications for radiation field design. Pract Radiat Oncol. 2011;1(2):115-125.

45. Mitchell DM, Perry L, Smith S, et al. Assessing the effect of a contouring protocol on postprostatectomy radiotherapy clinical target volumes and interphysician variation. Int J Radiat Oncol Biol Phys. 2009;75(4): 990-993.

46. Sidhom MA, Kneebone AB, Lehman M, et al. Post-prostatectomy radiation therapy: consensus guidelines of the Australian and New Zealand Radiation Oncology Genito-Urinary Group. Radiother Oncol. 2008; 88(1):10-19.

47. Michalski JM, Lawton C, El Naqa I, et al. Development of RTOG consensus guidelines for the definition of the clinical target volume for postoperative conformal radiation therapy for prostate cancer. Int J Radiat Oncol Biol Phys. 2010;76(2):361-368.

48. Poortmans P, Bossi A, Vandeputte K, et al. Guidelines for target volume definition in post-operative radiotherapy for prostate cancer, on behalf of the EORTC Radiation Oncology Group. Radiother Oncol. 2007;84(2): 121-127.

49. Malone S, Croke J, Roustan-Delatour N, et al. Postoperative radiotherapy for prostate cancer: a comparison of four consensus guidelines and dosimetric evaluation of 3D-CRT versus tomotherapy IMRT. Int J Radiat Oncol Biol Phys. 2012;84(3):725-732.

50. Croke J, Malone S, Roustan Delatour N, et al. Postoperative radiotherapy in prostate cancer: the case of the missing target. Int J Radiat Oncol Biol Phys. 2012;83(4):1160-1168.

51. Croke J, Maclean J, Nyiri B, et al. Proposal of a post-prostatectomy clinical target volume based on pre-operative MRI: volumetric and dosimetric comparison to the RTOG guidelines. Radiat Oncol. 2014;9(1):303. 
52. Jackson A, Marks LB, Bentzen SM, et al. The lessons of QUANTEC: recommendations for reporting and gathering data on dose-volume dependencies of treatment outcome. Int J Radiat Oncol Biol Phys. 2010;76(3 Suppl):S155-S160.

53. Casciani E, Polettini E, Carmenini E, et al. Endorectal and dynamic contrast-enhanced MRI for detection of local recurrence after radical prostatectomy. AJR Am J Roentgenol. 2008;190(5):1187-1192.

54. Cirillo S, Petracchini M, Scotti L, et al. Endorectal magnetic resonance imaging at 1.5 Tesla to assess local recurrence following radical prostatectomy using T2-weighted and contrast-enhanced imaging. Eur Radiol. 2009;19(3):761-769.

55. Rischke HC, Schäfer AO, Nestle U, et al. Detection of local recurrent prostate cancer after radical prostatectomy in terms of salvage radiotherapy using dynamic contrast enhanced-MRI without endorectal coil. Radiat Oncol. 2012;7:185.

56. Counago F, Cerro ED, Recio M, et al. Role of 3T multiparametric magnetic resonance imaging without endorectal coil in the detection of local recurrent prostate cancer after radical prostatectomy: the radiation oncology point of view. Scand J Urol. February 4, 2015. [Epub ahead of print.]

57. Barchetti F, Panebianco V. Multiparametric MRI for recurrent prostate cancer post radical prostatectomy and postradiation therapy. Biomed Res Int. 2014;2014:316272.

58. Zilli T, Jorcano S, Peguret N, et al. Dose-adapted salvage radiotherapy after radical prostatectomy based on an erMRI target definition model: toxicity analysis. Acta Oncol. 2014;53(1):96-102.

59. Zilli T, Jorcano S, Peguret N, et al. Results of dose-adapted salvage radiotherapy after radical prostatectomy based on an endorectal MRI target definition model. Am J Clin Oncol. September 18, 2014. [Epub ahead of print.]

60. Traudt K, Ciezki J, Klein EA. Low-dose-rate brachytherapy as salvage treatment of local prostate cancer recurrence after radical prostatectomy. Urology. 2011;77(6):1416-1419.

61. Gaztañaga M, Crook JM. Permanent seed brachytherapy for locally recurrent prostate cancer after radical prostatectomy: a case report and review of the literature. Brachytherapy. 2013;12(4):338-342.

62. Strom TJ, Wilder RB, Fernandez DC, et al. High-dose-rate brachytherapy with or without intensity modulated radiation therapy as salvage treatment for an isolated, gross local recurrence of prostate cancer post-prostatectomy. Brachytherapy. 2014;13(2):123-127.

63. Thompson IM, Valicenti RK, Albertsen P, et al. Adjuvant and salvage radiotherapy after prostatectomy: AUA/ASTRO guideline. $J$ Urol. 2013;190(2):441-449.

64. Dearnaley DP, Jovic G, Syndikus I, et al. Escalated-dose versus control-dose conformal radiotherapy for prostate cancer: long-term results from the MRC RT01 randomised controlled trial. Lancet Oncol. 2014;15(4):464-473.

65. Swanson GP, Hussey MA, Tangen CM, et al. Predominant treatment failure in postprostatectomy patients is local: analysis of patterns of treatment failure in SWOG 8794. J Clin Oncol. 2007;25(16):2225-2229.

66. Bellavita R, Massetti M, Abraha I, et al. Conformal postoperative radiotherapy in patients with positive resection margins and/or pT3-4 prostate adenocarcinoma. Int J Radiat Oncol Biol Phys. 2012;84(3):e299-e304.

67. Cozzarini C, Montorsi F, Fiorino C, et al. Need for high radiation dose ( $\geq 70 \mathrm{~Gy}$ ) in early postoperative irradiation after radical prostatectomy: a single-institution analysis of 334 high-risk, node-negative patients. Int J Radiat Oncol Biol Phys. 2009;75(4):966-974.

68. Bernard JR Jr, Buskirk SJ, Heckman MG, et al. Salvage radiotherapy for rising prostate-specific antigen levels after radical prostatectomy for prostate cancer: dose-response analysis. Int J Radiat Oncol Biol Phys. 2010;76(3):735-740.

69. Ohri N, Dicker AP, Trabulsi EJ, Showalter TN. Can early implementation of salvage radiotherapy for prostate cancer improve the therapeutic ratio? A systematic review and regression meta-analysis with radiobiological modelling. Eur J Cancer. 2012;48(6):837-844.

70. King CR, Spiotto MT. Improved outcomes with higher doses for salvage radiotherapy after prostatectomy. Int J Radiat Oncol Biol Phys. 2008;71(1):23-27.
71. Shelan M, Abo-Madyan Y, Welzel G, et al. Dose-escalated salvage radiotherapy after radical prostatectomy in high risk prostate cancer patients without hormone therapy: outcome, prognostic factors and late toxicity. Radiat Oncol. 2013;8:276.

72. King CR. The timing of salvage radiotherapy after radical prostatectomy: a systematic review. Int J Radiat Oncol Biol Phys. 2012;84(1):104-111.

73. Sassowsky M, Gut P, Hölscher T, et al. Use of EORTC target definition guidelines for dose-intensified salvage radiation therapy for recurrent prostate cancer: results of the quality assurance program of the randomized trial SAKK 09/10. Int J Radiat Oncol Biol Phys. 2013;87(3): 534-541.

74. Fowler JF, Ritter MA, Fenwick JD, Chappell R. How low is the alpha/ beta ratio for prostate cancer? Int J Radiat Oncol Biol Phys. 2003;57(2): 593-585.

75. Duchesne GM, Peters LJ. What is the alpha/beta ratio for prostate cancer? Rationale for hypofractionated high-dose-rate brachytherapy. Int J Radiat Oncol Biol Phys. 1999;44(4):747-748.

76. Dasu A. Is the alpha/beta value for prostate tumours low enough to be safely used in clinical trials? Clin Oncol ( $R$ Coll Radiol). 2007;19(5):289-301.

77. Miralbell R, Roberts SA, Zubizarreta E, Hendry JH. Dose-fractionation sensitivity of prostate cancer deduced from radiotherapy outcomes of 5,969 patients in seven international institutional datasets: alpha/beta $=$ 1.4 (0.9-2.2) Gy. Int J Radiat Oncol Biol Phys. 2012;82(1):e17-e24.

78. Dearnaley D, Syndikus I, Sumo G, et al. Conventional versus hypofractionated high-dose intensity-modulated radiotherapy for prostate cancer: preliminary safety results from the CHHiP randomised controlled trial. Lancet Oncol. 2012;13(1):43-54.

79. Yeoh EE, Holloway RH, Fraser RJ, et al. Hypofractionated versus conventionally fractionated radiation therapy for prostate carcinoma: updated results of a phase III randomized trial. Int J Radiat Oncol Biol Phys. 2006;66(4):1072-1083.

80. Pollack A, Walker G, Horwitz EM, et al. Randomized trial of hypofractionated external-beam radiotherapy for prostate cancer. J Clin Oncol. 2013;31(31):3860-3868.

81. Massaccesi M, Cilla S, Deodato F, et al. Hypofractionated intensitymodulated radiotherapy with simultaneous integrated boost after radical prostatectomy: preliminary results of a phase II trial. Anticancer Res. 2013;33(6):2785-2789.

82. Ippolito $\mathrm{E}$, Cellini $\mathrm{N}$, Digesù $\mathrm{C}$, et al. Postoperative intensity-modulated radiotherapy with simultaneous integrated boost in prostate cancer: a dose-escalation trial. Urol Oncol. 2013;31(1):87-92.

83. Cozzarini C, Fiorino C, Di Muzio N, et al. Hypofractionated adjuvant radiotherapy with helical tomotherapy after radical prostatectomy: planning data and toxicity results of a Phase I-II study. Radiother Oncol. 2008;88(1):26-33.

84. Kruser TJ, Jarrard DF, Graf AK, et al. Early hypofractionated salvage radiotherapy for postprostatectomy biochemical recurrence. Cancer. 2011;117(12):2629-2636

85. Katayama S, Habl G, Kessel K, et al. Helical intensity-modulated radiotherapy of the pelvic lymph nodes with integrated boost to the prostate bed - initial results of the PLATIN 3 trial. BMC Cancer. 2014;14:20.

86. Gladwish A, Loblaw A, Cheung P, et al. Accelerated hypofractioned postoperative radiotherapy for prostate cancer: a prospective phase I/II study. Clin Oncol (R Coll Radiol). 2015;27(3):145-152.

87. Cozzarini C, Fiorino C, Deantoni, et al. Higher-than-expected severe (Grade 3-4) late urinary toxicity after postprostatectomy hypofractionated radiotherapy: a single-institution analysis of 1176 patients. Eur Urol. 2014;66(6):1024-1030.

88. Michalski JM, Yan Y, Watkins-Bruner D, et al. Preliminary toxicity analysis of 3-dimensional conformal radiation therapy versus intensity modulated radiation therapy on the high-dose arm of the Radiation Therapy Oncology Group 0126 prostate cancer trial. Int J Radiat Oncol Biol Phys. 2013;87(5):932-938.

89. Nath SK, Sandhu AP, Rose BS, et al. Toxicity analysis of postoperative image-guided intensity-modulated radiotherapy for prostate cancer. Int J Radiat Oncol Biol Phys. 2010;78(2):435-441. 
90. Riou O, Fenoglietto P, Laliberté B, et al. Three years of salvage IMRT for prostate cancer: results of the Montpellier cancer center. ISRN Urol. 2012;2012:391705.

91. Bastasch MD, Teh BS, Mai WY, et al. Post-nerve-sparing prostatectomy, dose-escalated intensity-modulated radiotherapy: effect on erectile function. Int J Radiat Oncol Biol Phys. 2002;54(1):101-106.

92. Ost P, Fonteyne V, Villeirs G, Lumen N, Oosterlinck W, De Meerleer G. Adjuvant high-dose intensity-modulated radiotherapy after radical prostatectomy for prostate cancer: clinical results in 104 patients. Eur Urol. 2009;56(4):669-675.

93. Safdieh JJ, Schwartz D, Weiner J, et al. Long-term tolerance and outcomes for dose escalation in early salvage post-prostatectomy radiation therapy. Radiat Oncol J. 2014;32(3):179-186.

94. Berlin A, Cho E, Kong V, et al. Phase 2 trial of guideline-based postoperative image guided intensity modulated radiation therapy for prostate cancer: toxicity, biochemical, and patient-reported health-related quality-of-life outcomes. Pract Radiat Oncol. April 17, 2015. [Epub ahead of print.]

95. Goenka A, Magsanoc JM, Pei X, et al. Improved toxicity profile following high-dose postprostatectomy salvage radiation therapy with intensity-modulated radiation therapy. Eur Urol. 2011;60(6): 1142-1148.

96. Koontz BF, Das S, Temple K, et al. Dosimetric and radiobiologic comparison of $3 \mathrm{D}$ conformal versus intensity modulated planning techniques for prostate bed radiotherapy. Med Dosim. 2009; 34(3):256-260.

97. Davidson MT, Blake SJ, Batchelar DL, Cheung P, Mah K. Assessing the role of volumetric modulated arc therapy (VMAT) relative to IMRT and helical tomotherapy in the management of localized, locally advanced, and post-operative prostate cancer. Int J Radiat Oncol Biol Phys. 2011;80(5):1550-1558

98. Haworth A, Paneghel A, Herschtal A, et al. Verification of target position in the post-prostatectomy cancer patient using cone beam CT. J Med Imaging Radiat Oncol. 2009;53(2):212-220.

99. Fiorino C, Foppiano F, Franzone P, et al. Rectal and bladder motion during conformal radiotherapy after radical prostatectomy. Radiother Oncol. 2005;74(2):187-195.

100. Bell LJ, Cox J, Eade T, Rinks M, Kneebone A. The impact of rectal and bladder variability on target coverage during post-prostatectomy intensity modulated radiotherapy. Radiother Oncol. 2014;110(2):245-250.

101. Langen KM, Jones DT. Organ motion and its management. Int J Radiat Oncol Biol Phys. 2001;50(1):265-278.

102. Klayton T, Price R, Buyyounouski MK, et al. Prostate bed motion during intensity-modulated radiotherapy treatment. Int J Radiat Oncol Biol Phys. 2012;84(1):130-136.

103. Huang K, Palma DA, Scott D, et al. Inter- and intrafraction uncertainty in prostate bed image-guided radiotherapy. Int J Radiat Oncol Biol Phys. 2012;84(2):402-407.

104. Song S, Yenice KM, Kopec M, Liauw SL. Image-guided radiotherapy using surgical clips as fiducial markers after prostatectomy: a report of total setup error, required PTV expansion, and dosimetric implications. Radiother Oncol. 2012;103(2):270-274.

105. Fortin I, Carrier JF, Beauchemin MC, Béliveau-Nadeau D, Delouya G, Taussky D. Using fiducial markers in the prostate bed in postprostatectomy external beam radiation therapy improves accuracy over surgical clips. Strahlenther Onkol. 2014;190(5):467-471.

106. Langenhuijsen JF, Donker R, McColl GM, Kiemeney LA, Witjes JA, van Lin EN. Postprostatectomy ultrasound-guided transrectal implantation of gold markers for external beam radiotherapy. Technique and complications rate. Strahlenther Onkol. 2013;189(6):476-481.

107. Canter D, Kutikov A, Horwitz EM, Greenberg RE. Transrectal implantation of electromagnetic transponders following radical prostatectomy for delivery of IMRT. Can J Urol. 2011;18(4):5844-5848.

108. Zhu M, Bharat S, Michalski JM, Gay HA, Hou WH, Parikh PJ. Adaptive radiation therapy for postprostatectomy patients using real-time electromagnetic target motion tracking during external beam radiation therapy. Int J Radiat Oncol Biol Phys. 2013;85(4):1038-1044.
109. Ålander E, Visapää H, Kouri M, Keyriläinen J, Saarilahti K, Tenhunen M. Gold seed fiducials in analysis of linear and rotational displacement of the prostate bed. Radiother Oncol. 2014;110(2):256-260.

110. Schiffner DC, Gottschalk AR, Lometti M, et al. Daily electronic portal imaging of implanted gold seed fiducials in patients undergoing radiotherapy after radical prostatectomy. Int J Radiat Oncol Biol Phys. 2007;67(2):610-619.

111. Bell LJ, Cox J, Eade T, Rinks M, Kneebone A. Prostate bed motion may cause geographic miss in post-prostatectomy image-guided intensity-modulated radiotherapy. $J$ Med Imaging Radiat Oncol. 2013;57(6):725-732

112. Diot Q, Olsen C, Kavanagh B, Raben D, Miften M. Impact of anatomical interventions on the localization of post-prostatectomy cancer patients. Med Phys. 2010;37(2):629-637.

113. Diot Q, Olsen C, Kavanagh B, Raben D, Miften M. Dosimetric effect of online image-guided anatomical interventions for postprostatectomy cancer patients. Int J Radiat Oncol Biol Phys. 2011;79(2): 623-632.

114. Showalter TN, Nawaz AO, Xiao Y, Galvin JM, Valicenti RK. A cone beam CT-based study for clinical target definition using pelvic anatomy during postprostatectomy radiotherapy. Int J Radiat Oncol Biol Phys. 2008;70(2):431-436.

115. Ost P, De Meerleer G, De Gersem W, Impens A, De Neve W. Analysis of prostate bed motion using daily cone-beam computed tomography during postprostatectomy radiotherapy. Int J Radiat Oncol Biol Phys. 2011;79(1):188-194.

116. Sandhu A, Sethi R, Rice R, et al. Prostate bed localization with imageguided approach using on-board imaging: reporting acute toxicity and implications for radiation therapy planning following prostatectomy. Radiother Oncol. 2008;88(1):20-25.

117. Wong GW, Palazzi-Churas KL, Jarrard DF, et al. Salvage hypofractionated radiotherapy for biochemically recurrent prostate cancer after radical prostatectomy. Int J Radiat Oncol Biol Phys. 2008;70(2): $449-455$

118. Teh BS, Mai WY, Augspurger ME, et al. Intensity modulated radiation therapy (IMRT) following prostatectomy: more favorable acute genitourinary toxicity profile compared to primary IMRT for prostate cancer. Int J Radiat Oncol Biol Phys. 2001;49(2):465-472.

119. Arcangeli S, Saracino B, Petrongari MG, et al. Analysis of toxicity in patients with high risk prostate cancer treated with intensity-modulated pelvic radiation therapy and simultaneous integrated dose escalation to prostate area. Radiother Oncol. 2007;84(2):148-155.

120. Eldredge HB, Studenski M, Keith SW, et al. Post-prostatectomy imageguided radiation therapy: evaluation of toxicity and inter-fraction variation using online cone-beam CT. J Med Imaging Radiat Oncol. 2011;55(5):507-515.

121. Ghilezan MJ, Jaffray DA, Siewerdsen JH, et al. Prostate gland motion assessed with cine-magnetic resonance imaging (cine-MRI). Int $J$ Radiat Oncol Biol Phys. 2005;62(2):406-417.

122. Padhani AR, Khoo VS, Suckling J, Husband JE, Leach MO, Dearnaley DP. Evaluating the effect of rectal distension and rectal movement on prostate gland position using cine MRI. Int J Radiat Oncol Biol Phys. 1999;44(3):525-533.

123. Smeenk RJ, Teh BS, Butler EB, van Lin EN, Kaanders JH. Is there a role for endorectal balloons in prostate radiotherapy? A systematic review. Radiother Oncol. 2010;95(3):277-282.

124. Smeenk RJ, van Lin EN, van Kollenburg P, McColl GM, Kunze-Busch $\mathrm{M}$, Kaanders JH. Endorectal balloon reduces anorectal doses in postprostatectomy intensity-modulated radiotherapy. Radiother Oncol. 2011;101(3):465-470.

125. Jameson MG, De Leon J, Windsor AA, et al. Endorectal balloons in the post prostatectomy setting: do gains in stability lead to more predictable dosimetry? Radiother Oncol. 2013;109(3):493-497.

126. de Leon JF, Jameson MG, Windsor A, et al. Superior target volume and organ stability with the use of endorectal balloons in postprostatectomy radiotherapy. J Med Imaging Radiat Oncol. April 1, 2015. [Epub ahead of print.] 
127. Ishiyama H, Teh BS, Blanco AI, et al. Salvage intensity modulated radiotherapy using endorectal balloon after radical prostatectomy: clinical outcomes. Int J Urol. 2013;20(12):1178-1183.

128. Sonn GA, Sadetsky N, Presti JC, Litwin MS. Differing perceptions of quality of life in patients with prostate cancer and their doctors. J Urol. 2009;182(5):2296-2302.

129. Litwin MS, Lubeck DP, Henning JM, Carroll PR. Differences in urologist and patient assessments of health related quality of life in men with prostate cancer: results of the CaPSURE database. J Urol. 1998;159(6):1988-1992.

130. McVey G, McNair H, Morgan S, Hansen VN, Bulbrook L, Dearnaley DP. Improving the accuracy of prostate radiotherapy: assessment of a novel rectal obturator (ProSpare) and gold grain markers. Radiother Oncol. 2010;96 Suppl 1:S405.
131. Alexander E, McNair H, Landeg S, Hansen V, Dearnaley D. Initial results of a prospective clinical trial examining a novel rectal obturator to localise the prostate and spare the rectum during radical prostate radiotherapy. Clin Oncol. 2014;26(2):e3.

132. Murray JR, Gulliford S, Alexander EJ, McNair H, Dearnaley DP. The effect of ProSpare, a rectal obturator on anorectal doses in prostate radiotherapy. Eur Urol Suppl. 2014;13(5):119.

\section{Publish your work in this journal}

Cancer Management and Research is an international, peer-reviewed open access journal focusing on cancer research and the optimal use of preventative and integrated treatment interventions to achieve improved outcomes, enhanced survival and quality of life for the cancer patient. The journal welcomes original research, clinical \& epidemiological studies, reviews \& evaluations, guidelines, expert opinion \& commentary, case reports \& extended reports. The manuscript management system is completely online and includes a very quick and fair peerreview system, which is all easy to use. Visit http://www.dovepress.com/ testimonials.php to read real quotes from published authors. 